\title{
Interdisciplinary Studies of Childhood Ethics: Developing a New Field of Inquiry
}

\author{
Franco A. Carnevale*, Angela Campbell ${ }^{\dagger}$, Delphine Collin-Vézina ${ }^{\S}$ and Mary Ellen Macdonald \\ *Ingram School of Nursing, Department of Pediatrics, Biomedical Ethics Unit, Counselling \\ Psychology, McGill University, Montreal OC, Canada \\ ${ }^{\dagger}$ Faculty of Law, McGill University, Montreal QC, Canada \\ §Tier II Canadian Research Chair in Child Welfare, School of Social Work, McGill University, \\ Montreal QC, Canada \\ 'Division of Oral Health and Society, Faculty of Dentistry, McGill University, Montreal OC, Canada
}

The principal aim of this investigation was to help develop 'Interdisciplinary Studies of Childhood Ethics' as a new field of inquiry. We identified: (i) current intra-disciplinary and interdisciplinary knowledge gaps in childhood ethics; and (ii) priorities for future research and development. A prominent problem, highlighted within and across disciplines, relates to how the best interests standard should be reconciled with the recognition of children as agents. This project makes an innovative contribution by promoting the development of interdisciplinary childhood ethics knowledge and standards, informing future improvements in childhood research and services. (C) 2013 John Wiley \& Sons Ltd and National Children's Bureau

Keywords: agency, best interests, child protection, childhood, childhood education, ethics, health \& well-being, interdisciplinary, law.

\section{Introduction}

Drawing on a 2-year collaborative study, this article advances a new field of inquiry that we have called: Interdisciplinary Studies of Childhood Ethics. A growing body of literature has addressed a wide range of ethical concerns relating to children and childhood. Yet, significant knowledge gaps persist.

The aims of our investigation were to: (i) identify current knowledge gaps in childhood ethics; (ii) identify priorities for future research and development; and (iii) develop a programme of research to address these priorities. This study makes innovative contributions by promoting the development of interdisciplinary childhood ethics knowledge and standards that inform future improvements in childhood research and services.

In this article: (i) 'ethical' and 'moral' are used interchangeably, as is common in ethics discourse; (ii) 'childhood' refers both to children as a population and childhood as a field of inquiry; (iii) 'children' refers to all minors (age of majority varies from 18 to 21 years in North America); (iv) 'medical' refers to all health sciences and services; (v) 'the law' and 'law' are used interchangeably to refer to state-made norms developed by courts and legislatures within Western legal traditions; and (vi) 'Western' refers to dominant sociocultural outlooks and practices associated with Western Europe and North America.

\section{Background}

Interdisciplinary research is increasingly recognised as a necessary direction for scholarly inquiry (Moran, 2001). 'Childhood studies' is a notable example of interdisciplinary inquiry (Pufall and Unsworth, 2004). Yet, much childhood research remains largely discipline-bound, 
perpetuating ongoing intellectual fragmentation. One domain where this is the case is "childhood ethics'. For the purposes of this article, 'childhood ethics' implies all knowledge and practices relating to childhood matters of right/wrong, good/bad, or just/unjust.

The prevailing Western ethical framework for children is centred on the 'best interests' standard (Miller, 2010). This standard mirrors the law's approach to children, which aims to ensure that children benefit from the greatest possible outcomes within their respective circumstances. In the law, children are not recognised as fully autonomous agents capable of moral reasoning or assuming full responsibility for their choices and conduct. Thus, they are not endowed with the full set of rights and duties extended to competent persons of full age. They are perceived to acquire agency gradually, as they mature and become adults. Given the vulnerability of children, in particular their inability to exercise their rights fully and independently, and the physical and emotional limits on their ability to articulate their own interests and concerns, surrogate actors are given the power to make decisions on their behalf. Such surrogates, typically the child's parents, are presumed to act in a child's best interests. Where this is questioned, the state may intervene to implement actions deemed more conducive to promoting the child's best interests.

Notwithstanding important contributions from such normative developments, there are significant intra-disciplinary and interdisciplinary knowledge gaps relating to childhood ethics (Miller, 2010). There is a lack of truly interdisciplinary studies in this domain. There are problems within individual disciplines; divisions between childhood education, legal and social service providers and social science and humanities researchers; as well as divisions within the medical sciences, social sciences and the humanities in their examination of medical ethics for childhood. Furthermore, little integration of knowledge among the fields of social services, childhood education and medical services ethics research has been advanced, resulting in significant gaps and inconsistencies in standards and practices relating to children.

\section{Methods}

\section{Theoretical framework}

Our analysis drew on two interrelated frameworks: interdisciplinary and ethics. We employed an interdisciplinary framework (Moran, 2001), as developed in 'childhood studies' (Pufall and Unsworth, 2004). This approach assumed value in individual disciplinary contributions, which are enriched through transversal interdisciplinary analyses and integration.

Second, despite the diverse philosophical approaches in ethics (e.g. consequentialist, deontological, virtue ethics) that have addressed selected childhood concerns (Miller, 2010), a social constructivist (Guba, 1990) ethical framework was developed for this investigation to ensure the interdisciplinary commitment described above. This framework allowed us to examine the various ways childhood ethics has been articulated within and across disciplines; focusing on how children are understood as moral entities. The moral status of children is constructed through social processes and articulated through textual forms (e.g. legislation, scholarly reports). The child can be construed as a moral object towards whom others have interests and obligations, as well as a moral subject with a subjective moral life, agential capacities and responsibilities towards others. Moreover, childhood is constructed from a diversity of social perspectives, such as son/daughter, citizen, community member, student and patient.

This examination of childhood ethics involved knowledge relating childhood to matters of right/wrong, good/bad or just/unjust. This included: (i) normative sources (e.g. legislation, case law, ethics codes); (ii) empirical evidence describing moral phenomena and how these are affected by social/cultural contexts; (iii) theoretical and methodological frameworks; and (iv) policies and guidelines that define practices relating to childhood ethical matters. 


\section{Design}

This investigation was conducted from 2010 to 2012. The first phase of the project addressed the question 'What do we know?' about childhood ethics through a critical examination of current knowledge. The second phase examined 'What do we need to know?', which focused on identifying priorities for future research and development. Given this vast scope, our analysis focused primarily on the North American context, but yields findings that may bear relevance in other settings.

Using a scoping review framework (Arksey and 0'Malley, 2005), this study involved two main activities: (i) analyses of published texts; and (ii) consultations with experts across relevant disciplines, conducted through an Interdisciplinary Panel of Expert Consultants convened for this project (see Acknowledgements). These experts recommended text sources, search strategies and assisted with the interpretation of analyses. Guiding Questions were developed to orient the strategies used to identify and analyse texts; for example, Text Identification Questions (examples): Which disciplines and sources should be searched to identify childhood notions of good/bad, right/wrong, or just/unjust?; Text Analysis Questions (examples): How are children and childhood construed ethically in this text?; Which ethical questions or problems are addressed? Which are not addressed?

\section{Findings}

Our analysis identified numerous intra-disciplinary and interdisciplinary themes and knowledge gaps. Priority concerns in childhood ethics are described below from selected disciplinary perspectives: law, psychology, education, medical sciences, child welfare and social studies; continually examined with a focus on interdisciplinary intersections. This is followed by an examination of the principal transversal domain of concern identified; the intersection of best interests and agency.

In general, we have not framed this analysis in terms of age thresholds, to guard against the dominant 'capable/incapable' polemic conception of childhood, which underlies the major ethical problems identified in our investigation.

Due to space constraints, the full body of materials examined for this investigation could not be listed; only selected references are cited. Moreover, our analyses of research ethics have been excluded because of space constraints; although we have reviewed selected research ethics concerns elsewhere (Carnevale and others, 2008). For example, advances in this domain have highlighted that: (i) children's capacities to understand and actively make decisions in matters affecting them are commonly under-appreciated; (ii) the potential harms of participating in non-therapeutic research are frequently exaggerated; and (iii) 'assent' can be better developed as a framework for recognising agency among some children. This study has informed the analyses reported in this article.

\section{Child law}

The conception of the child within the law was examined across various contexts, including child as patient, research subject, tortfeasor, victim or witness, accused or offender, as well as citizen and rights holder. Some key sources that framed our thinking in this section included: Archard and Macleod, 2002; Campbell and others, 2011; Dwyer, 2006; Eekelaar, 1992; Fortin, 2004; Minow, 1986; Monk, 2002; Roche, 1999; Van Praagh, 2005.

Analyses discerned the child's multiple and overlapping identities in law, with two principal themes: (i) children are vulnerable and require protection; (ii) children have a degree of agency and bear responsibilities towards themselves, other private actors and the 
state. In some legal categories, children may be regarded as simultaneously vulnerable and autonomous (e.g. juvenile offenders).

In a recent article, we argued that understanding the child through the singular lens of rights, without a concomitant contemplation of obligations, overlooks the extent to which recognising obligations for children facilitates their development of citizenship and agency (Campbell and others, 2011). Yet to substantiate a child's citizenship and agency, obligations for children must be understood from a contextual perspective that accounts for the child's embeddedness within her particular social context and relationships.

The concept of 'ethics' has an amorphous place in law; it is often linked to legal practice. Specifically, 'legal ethics' is understood in deontological terms, embodying obligations jurists have to their clients, profession and the broader public. 'Ethics' seems even more inchoate when considered with reference to children. The place of children in the law is undetermined, and shifts according to context. Jurists faced with matters involving children rarely speak in terms of 'ethics'. Instead, concepts of rights, interests, benefits and stakes for children are more resonant with legal traditions. Nevertheless, a nexus between law, ethics and children is discernible in a couple of contexts.

First, it is arguable that being accorded an opportunity to express one's views and wishes is a paramount tenet of childhood ethics from a legal perspective. Children's right to have their interests known and their voices heard in matters that broach their interests is a principle enshrined in international and national law. This tenet is affirmed by legal scholars and courts at all levels. Yet, an issue arises as to whether this ethical principle embraced by formal law is practical or aspirational. Many questions, which either remain unanswered or have been answered ambiguously or incompletely, complicate the application of the child's right to be heard. For example, do all children merit the opportunity to be heard or just those above a certain age? What weight should be attributed to a child's opinion? How should legal actors ascertain a child's views and wishes? Such questions surface in a range of settings, including custody claims in family law, issues regarding child protection and adoption and assessments of a child's ability to consent to or to refuse medical care.

A second key legal principle can be articulated: in all matters that affect her, a child's best interests must be a decision-maker's paramount concern. This is a broad proposition that has some grounding in ethics and seeks to provide a framework for justice in issues affecting children. The 'best interests of the child' principle is enshrined both in international and local legislation of both general and particular (e.g. family law, child welfare law) application. The principle is also subject to certain difficulties with respect to application. For instance, it is critiqued for being too malleable, for yielding unpredictable results and for infusing judicial decision-makers with too much discretion.

These two expansive ethical principles are integrated into formal law that reflects legal perceptions of childhood. Whether and how these principles translate into concrete rights and obligations for children is unclear. Although there are various legal sources that delineate rights for children, jurists have yet to thoroughly canvass the presence and relevance of children's legal obligations (Campbell and others, 2011).

Interdisciplinary knowledge is essential to legal appreciations of childhood ethics given the need for jurists to grapple with matters affecting children that fall outside their expertise. In particular, medical and psychological knowledge is required to appreciate whether a child can understand her circumstances and make informed decisions. Moreover, sociological perspectives offer insight into whether law's expectations and presumptions live out in the lives of children. 


\section{Child psychology}

Moral development (i.e. conceptions of the maturation of children's moral capacities) is a principal theme identified throughout the interdisciplinary literature examined for this investigation. Two prominent approaches have contended with moral development in child psychology. Following the early work of Kohlberg and Piaget, the first is rooted in cognitive development, described as an invariant sequence of stages (Perkins and Turiel, 2007). Researchers from this tradition seek to uncover the processes and factors that characterise the developmental changes in children's reasoning in morally relevant contexts. Gilligan (1982) contested much of this work as male-centred conceptions of moral development.

The second is rooted in the socialisation tradition which emphasises consistency and stability of observed variation in emotion, behaviour and cognition across contexts and time as well as variation in children's individual trajectories (Kochanska and others, 1997). Researchers seek to understand the processes and factors that account for this variation in morally relevant contexts.

Some specific themes in moral development, relevant for questions throughout this investigation, are described below.

The development of a child's conscience emerges in the first 3 years of life, intimately related to the growth of other competencies (e.g. self-awareness/self-control) (Kochanska and others, 1997). The coherence among early manifestations of conscience remains poorly understood. A child's early family relationships are considered especially important in the development of early conscience and moral development as these provide early experience with behavioural and moral standards (Laible and Thompson, 2000).

Socialisation research underscores affective, relational and dialogical bases of morality, emphasising the role of parenting in moral internalisation (Arsenio and Kramer, 1992). Researchers differ in the importance they assign to moral cognition and emotion in the genesis of prosocial, morally relevant behaviour. Cognitive-structural theorists emphasise moral judgments based on universal norms; other researchers highlight moral emotions as the basic motive for moral actions. Most developmentalists believe that in the second year, young children begin to be aware of their 'transgressions' and can subsequently experience discomfort. Young children can distinguish moral violations from conventional violations and can understand that it is objectively wrong to hurt others (Cushman, 2008).

When preschool children were asked to examine the violation of a moral norm and judge the feelings of the victimiser, victimisers were thought to feel positive emotions, while victims were thought to experience negative emotions (Arsenio and Kramer, 1992). These findings conflict with socio-moral theories which argue that an awareness of victim harm and fear of external sanctions should lead children to expect victimisers to feel negative emotions.

Early parenting and components of child temperament appear critical in shaping children's internalisation of rules and in predicting subsequent conduct problems (Kochanska and others, 1997); yet, little is known about the processes that underlie these assumptions. Gasser and Keller (2009) found that primary school bullies are socially competent in terms of cognitive and affective perspective-taking skills but score lower than prosocial children on the dimension of moral competence with a particular deficit in moral motivation. Some theories have focused primarily on moral thought rather than moral conduct; for example, demonstrating how people may justify their actions and commit immoral behaviours through 'Moral Disengagement' (Bandura and others, 1996). Little is known about how moral disengagement develops. 


\section{Childhood education}

Education scholars are particularly challenged by two interrelated aspects of childhood ethics: schools are expected to play a significant role in promoting children's moral development, while also managing ethical challenges inherent in education.

In North America, education is generally regarded as both a right and a duty for children (DiGiulio, 2001; Dwyer, 2006; Eekelaar, 1992; Monk, 2002). Parents have a duty to send their children to school, and educators, as central actors in children's development, have a duty to help them become contributing members of society by conveying socially acceptable values through moral education.

Children enjoy rights as students, including freedom of religion and expression, and an expectation of privacy. Schools are expected to accommodate students' beliefs and practices, however, certain limits can be placed on children's liberties in light of safety considerations. Furthermore, codes of conduct require that children behave in a socially acceptable manner with respect to their peers and school authorities.

Schools have become increasingly concerned about certain Internet practices, such as cyber-bullying (Shariff, 2009); however, the school's role in this domain remains unclear. Although schools have a responsibility to maintain a safe environment for students and faculty, it is difficult for them to intervene in the realm of online communication and social networking. This is partly attributable to ambiguities in current conceptions of agency and responsibility in childhood (Campbell and others, 2011).

Elsewhere, we examined selected legal considerations of the child as student, highlighting obligations that befall children at school (Campbell and others, 2011). The law offers a framework for appreciating obligations for children oriented towards a textured recognition of their dignity, agency and citizenship. The parameters law sets for children's obligations highlights their ongoing connections with and frequent reliance on others. This study warns against the imposition of unrealistic obligations that fail to account for the realities of youth, particularly those who are most vulnerable socially and economically.

Priority ethical questions in schooling that require further investigation include: Who is ultimately responsible for children's moral education?; Because children learn about socialisation at school, what can be said about children's contribution to each other's education?; How may the law be useful in providing a framework for schools to intervene when harmful online communication takes place?

\section{Paediatric medicine}

Paediatric medicine has drawn on adult-centred bioethics, research ethics standards for children, developmental paediatrics and psychology, as well as child medical law in the development of paediatric bioethics. This field has addressed several ethical problems relating to children.

North American medical societies have stated that, for children who cannot give consent themselves, parents should be responsible for granting permission for treatment, giving weight to the child's views when possible (AAP, 1995; CPS, 2004). Treatment decisions should be based on the best interests standard, weighing the balance of benefits and burdens of treatment options for the child. This is consistent with the prevailing bioethical and legal norms regarding the care of children in North America (Miller, 2010). In cases where physicians disagree with parental wishes, court authorisation is needed to provide refused medical care.

The best interests standard presents significant challenges in clinical practice, relating to how to define - and who should define — best interests (Miller, 2010). Treatment decisions commonly involve a weighing of value-laden 'goods' (e.g. sanctity of life versus quality of 
life), without an agreed-upon hierarchy of values to determine how these goods should be ranked. Given these operational challenges relating to best interests, clinicians and parents (and sometimes children as well) are frequently confronted with disagreements over what is best for a child (Carnevale, 2012). Although paediatric clinicians should ordinarily defer to parents' assessments of best interests, clinicians are also required to ensure that parents' actions are in line with a child's best interests.

A growing debate relates to the importance that should be accorded to children's views (Carnevale, 2012). It is increasingly recognised that adolescents can and perhaps should make some treatment decisions without requiring parental 'corroboration' (CPS, 2004). For younger children, there is some recognition that their assent should be solicited — although the moral importance of assent in clinical care is undeveloped, unlike the paediatric research ethics context (Bluebond-Langner, 1978; Carnevale and others, 2008).

Finally, current paediatric decision-making standards result in an individualist ethic; based exclusively on what is best for the child. Paediatric clinicians, however, are oriented to family-centred care, seeking to foster family well-being. Best interests standards require that clinicians ensure the child's interests are not trumped by those of others. It is not clear how clinicians should regard the ethical significance of others' interests (e.g. impact on siblings or parents); that is, how they should reconcile the child-patient's best interests with the interests of other family members (Miller, 2010).

The centring of clinical practice on the best interests standard results in a narrow construal of paediatric ethics. A child's interests dwell within a broader moral landscape of additional interests (e.g. interests of families, parents, siblings, clinicians, institutions, state). Moreover, the moral lives of these agents extend beyond the pursuit of their interests, to the exercise of rights, obligations and socioculturally transmitted mores, among other considerations (Carnevale, 2012).

\section{Child welfare}

Childhood ethics principles are cornerstones to child welfare practices. The work of child welfare professionals involves ethical tensions that take place at different levels of intervention. Child welfare workers are faced with troublesome, emotionally provoking ethical dilemmas: for example, placement of a maltreated child in a foster family; assessment of recidivism risk for delinquent youths. Decisions must be made on the basis of fundamental child welfare values that guide service provision (e.g. protection of children, preservation of families, respect for families, respect for persons, client self-determination, individualised intervention) and professional ideals (e.g. competence, loyalty, diligence, honesty, promise-keeping, confidentiality) (Simmons, 2003). To that end, child welfare workers rely on their codes of ethics to establish their ethical responsibilities towards themselves, clients, colleagues, employees and employing organisations, their profession and society. Nevertheless, discussions in this field are largely limited to practical, situation-based issues that focus on values, rules, standards and duties. As a consequence, child welfare is only beginning as a childhood ethics discipline; and the overarching beliefs that guide child welfare principles are yet to be uncovered.

In analysing child welfare legal norms, of particular interest are the ways in which children's voices are acknowledged and valued in decision-making. Embedded in the legal system, the child welfare system is vested with great power as 'services' can be made compulsory to children, youth and their carers, which is likely, at times, to create tension (Child Welfare Anti-Oppression Roundtable, 2009). Although the well-taken premise of this system is to provide services 'for the good of children and youth', engaging children and their families in the decision process is not routinely practised, albeit foundational to good 
casework practice (Alpert and Britner, 2005; Dawson and Berry, 2002). As a consequence, clients can feel unvoiced and unheard, or perceive a lack of control over the decisions that are made on their behalf by third parties (e.g. child welfare workers, attorneys, judges). The field could be enhanced by reviewing how children's opinions and agency can be better valued in decision-making, regulations and policies.

The important juxtaposition between youth protection law and youth criminal law also calls for a broader understanding of the ethical beliefs at play. It is not uncommon for the same children to be involved with both branches of child welfare law: youth protection law which regards children as vulnerable and potential victims of maltreatment (i.e. bearers of a right to protection) and youth criminal law which recognises children as potential perpetrators of criminal harms (i.e. bearers of responsibilities for their actions). Indeed, criminal charges emerging out of residential care facilities where children receive services under the youth protection law are commonplace (Finlay, 2007), including those related to youth gangs, gun violence, drug trafficking, prostitution and other issues that raise safety-related concerns. Yet there has been very little examination of how these branches of law intersect. A 'get tough on crime' mentality is frequently promoted by government and citizen groups where investigating wrong-doing and convicting the perpetrators are prioritised over more collaborative, preventative, or curative approaches (Gharabaghi, 2010). Issues of poverty and social alienation among particular demographic groups require further examination to better understand the intersection between experiences of maltreatment and criminal-related activities (Gharabaghi, 2010). This knowledge could alleviate obstacles to providing services to children that transcend these systemically entrenched yet often artificial divides.

\section{Social studies of childhood}

Social studies of childhood is an inherently interdisciplinary endeavour bringing together historical, theoretical and empirical research to puzzle through the questions: What is a child, What is childhood, and How are the answers to these questions both shaping of and shaped by, the sociocultural landscape? Some key sources that informed our thinking in this section included: Ariès, 1960; Armstrong, 1986; Bluebond-Langner, 1978; Lancy, 2008; Montgomery, 2008; Scheper-Hughes and Sargent, 1998; Zelizer, 1985.

Through examining discourses, narratives and cultural scripts relating to childhood, this field has contrasted universalist claims such as those found in rights-based discourses to notions of child and childhood which draw on local sociocultural meanings and practices. For instance, a Western notion of the child as an innocent 'tabula rasa' understands children as objects for socialisation, education and needing protection as they mature through developmental stages on their way to becoming legitimate social actors. This approach can be contrasted with understandings of children as inherently containing social value regardless of age or stage and whose participation in the social world is therefore inherently valuable.

Many tensions exist in this scholarship, leading to further challenging questions. For example, can children be seen both as vulnerable, in need of - and deserving of - protection, yet also legitimate social actors deserving of citizenship rights within the modern nation-state? Thinking of children as citizens requires theorising children's' rights, resources and membership as well as the concomitant obligations and duties that come with these privileges. Other uncomfortable discussions ensue when the practices of cultural groups and the needs of nation-states fly in the face of universalist rights-based discourses on children. For example, notions of child labour and the study of child soldiers stemming from an economic and political value of children sits in direct tension with Western notions of vulnerability and emotional value. 
To parse these perspectives requires advancing child-centred research methodologies and theories that move away from infantalising and patronising approaches to those that are authentically child-focused. Children's views and experiences need to be interpreted through child-centred frames; that is, not according to adult expectations and intellectual capacities. An ethical stance is motivating this field to take on this task, and thereby correct for an historical exclusion of children as legitimate research subjects. This exclusion has resulted in an absence of the child's voice in the empirical work and resultant theory development, with research products biased in favour of adult versions of children's experience and reality.

\section{A transversal challenge: the intersection of best interests and agency}

Best interests is the recognised standard for most matters affecting children. There is also a growing view that children should be heard to optimally determine their best interests. Although this advances a child-centred understanding, treating each child as unique, decisional authority is commonly held by adults responsible for the child. From a best interests perspective, children are generally regarded as incapable of making ethically significant decisions by themselves. Lee's (2001) analysis of the socio-historical construction of childhood highlights how this is rooted in a 19th century distinction between adults as capable and independent 'human beings' and children as incapable and dependent 'human becomings'.

Against this dominant conception of children as incapable, varying degrees of agency have been gradually recognised. Agency has not been uniformly defined but refers broadly to a person's capacity to act (Taylor, 1985). This is sometimes specified in terms of moral agency, referring to a person's capacity to act in the light of considerations of right and wrong. Children's choices and actions are recognised in selected circumstances (e.g. assent or refusal to participate in non-therapeutic research) or in some jurisdictions (e.g. consent to medical care among older adolescents).

Children are regarded both as incapable and as agents with capacities to act on their own. The juxtaposition of these two conceptions of the child underlies the leading questions in childhood ethics. Below, we review the interrelation and potential reconciliation of best interests and agency in childhood across selected disciplinary outlooks, followed by an integrated interdisciplinary perspective.

\section{Law}

It is important to examine how best interests analyses are deployed in the law, to show how legal actors and institutions make broad and often erroneous presumptions about what allows children to flourish. Future research should examine how the best interests standard has been used to reach outcomes that risk undermining or severing beneficial relationships between children and members of their families or communities. The ways in which legislatures and courts resist such relationships when they appear to risk 'harm' should be highlighted. Where a relationship is viewed as threatening in some way, law may intervene at the expense of the child's membership within and in connection to her community. This is customarily represented as a protection of children's best interests. Yet such efforts fail to account for the child's citizenship and agency. Examples that should be explored include: Aboriginal child welfare and adoption, interracial and intercultural custody litigation and medical decision-making by minors anchored to faith tenets that counter medical advice.

\section{Medicine}

Best interests perspective draws on a conception of children as incapable, dependent and in need of protection. Clinical and research evidence demonstrates, however, that children have a greater capacity to understand and act responsibly towards matters regarding their health 
than commonly recognised. Some research suggests their capacities can develop further when they are engaged in health-care decisions. The tension between construing children as incapable dependents or as capably autonomous gives rise to urgent questions such as: (i) Are best interests and agency necessarily opposed?; (ii) Should greater capacity entail a greater recognition of agency and if so, what does this entail for parental authority?; and (iii) What form of agency should be recognised among younger children who do not demonstrate formally defined decisional capacity?

\section{Child welfare}

Protecting children who are abused or neglected by their carers and others is the principal mandate of the child welfare system, though this is a shared responsibility with the community as a whole. The child welfare system is considered a last-resort option that is called upon when no other social structure has successfully addressed presenting concerns. The child welfare system has the legal power to act unilaterally for the 'protective good' of the child. However, a significant proportion of 'protected' children feel unheard or perceive a lack of control over decisions made on their behalf by third parties. It is important to examine how children are allowed to speak when making decisions in an investigation. How children's opinions are framed in regulations and policies should be examined. Moreover, future research should investigate whether everyday practices are in line with espoused policies.

\section{Social studies}

As the theoretical discourse of best interests is increasingly challenged by a growing counter-narrative grounded in empirical data of the child as citizen and agent, an important topic that requires attention is 'vulnerability'; especially how it is mobilised to justify actions done to protect children but thereby causing new harms. The tension between best interests and agency was perhaps first empirically uncovered by Bluebond-Langner (1978) in her research on children dying of cancer. She documented a profound moral harm caused to children in a context where they were considered too vulnerable to be agents involved in their own care. Learning from this study, in thinking about how best interests and agency might coexist in a clinical or research context, it is important to think seriously about the notion of vulnerability: can (or should) children be cast as both vulnerable and needing/ deserving of protection while at the same time agents with rights and responsibilities.

\section{Interdisciplinary integration}

Through the transversal interdisciplinary review of best interests and agency in the preceding section, we identified several problems that require further investigation. The best interests standard has been important in fostering child-centred orientations in multiple domains of children's lives; however, significant concerns persist regarding its operationalisation. There is no agreed-upon definition of this foundational concept, tacitly resulting in its construal according to the viewpoints of adults with decisional authority. It is not clear how the child's own viewpoints should be related to the determination of a child's best interests.

'Agency' needs to be more fully articulated for the context of childhood, highlighting how this concept may - or may not - apply across the phases of childhood. Agency should be distinguished from autonomy and self-determination. It should not be construed narrowly in terms of capacity to assume responsibility for one's actions, opting for a more inclusive construal that promotes the development of 'child-centred' outlooks. Although important strides have been made in hearing children's voices, these voices remain predominantly infantilised as children's views are commonly interpreted by adults through adult-centred outlooks. 
Finally, the interrelation of best interests and agency in childhood has been underexamined. These key concepts have emerged in an apparently polemic relationship: the best interests standard is commonly related to children as a protective measure until they develop their capacities to act as agents. Our analysis highlights that children can possess a wide range of agential capacities, calling for a widely inclusive conception of children as agents. We also recognise that children can be vulnerable across a number of contexts, supporting the need for protective standards such as best interests.

A paradigm shift is required. A new framework is needed to undo the current best interests/agency polemic and favour an outlook where best interests and agency can coexist and reciprocally enrich their recognition. Some examples can be drawn from adult models in the context of mental health or 'vulnerable elderly'. Such a framework should consider a 'thicker' conception of assent as an operational standard for contexts where consent would be unwarranted.

\section{Conclusion}

Childhood ethics is an emerging field of inquiry; yet it remains highly fragmented. Our investigation has identified intra-disciplinary and interdisciplinary knowledge gaps in childhood ethics as well as priorities for future research and development. A particularly prominent problem highlighted within and across disciplines relates to how the best interests standard should be reconciled with the recognition of children as agents.

Future research should also investigate childhood ethics from an international perspective, examining variations associated with sociocultural-political contexts; for example, diverse conceptions of decisional authority attributed to children, parents and state agents; varying values/norms underlying childhood standards; ethical concerns related to socioeconomic inequities, such as child labour or access to education.

Given the rich insights fostered by the interdisciplinary nature of this investigation, future development of childhood ethics frameworks, standards and research should be anchored in an interdisciplinary orientation. This will help ensure the richest understanding of the moral lives of children.

\section{Acknowledgements}

We gratefully acknowledge the valuable contributions of our Interdisciplinary Panel of Expert Consultants: Gilles Bibeau (anthropology), Myra Bluebond-Langner (anthropology), Barbara Gibson (clinical sciences; disability studies), Kathleen Glass (bioethics); Patricia McKeever (disability studies; sociology), Shaheen Shariff (education), Victoria Talwar (education; psychology), Nico Trocmé (child welfare; social work), Shauna Van Praagh (law), Daniel Weinstock (philosophy); as well as our Research Assistants: Marissa Carnevale (law), Franzina Coutinho (clinical sciences), Carole Federico (bioethics; psychology), Suzanne Jackson (law).

\section{Funding}

This work was supported by a Research Development Initiatives Grant from the Social Sciences \&t Humanities Research Council of Canada [grant number 820-2010-0033].

\section{References}

AAP: American Academy of Pediatrics. 1995. Informed consent, parental permission, and assent in pediatric practice. Pediatrics 95: 314-317. 
Alpert LT, Britner PA. 2005. Social workers' attitudes toward parents of children in child protective services: evaluation of a family-focused casework training program. Journal of Family Social Work 9: 33-64.

Archard D, Macleod C (eds.). 2002. The Moral and Political Status of Children. Oxford University Press: Oxford.

Ariès P. 1960 [1962]. L'Enfant et la vie familiale sous l'Ancien Régime [Centuries of Childhood: A Social History of Family Life]. Alfred Knopf: New York.

Arksey H, O'Malley L. 2005. Scoping studies: towards a methodological framework. International Journal of Social Research Methodology: Theory \&t Practice 8: 19-32.

Armstrong D. 1986. The invention of infant mortality. Sociology of Health \& Illness 8: 211-232.

Arsenio W, Kramer R. 1992. Victimizers and their victims: children's conception of the mixed emotional consequences of moral transgressions. Child Development 63: 915-927.

Bandura A, Capara GV, Barbaranelli C, Pastorelli C. 1996. Mechanisms of moral disengagement in the exercise of moral agency. Journal of Personality and Social Psychology 71: 364-374.

Bluebond-Langner M. 1978. The Private Worlds of Dying Children. Princeton University Press: Princeton, NJ.

Campbell A, Carnevale M, Jackson S, Carnevale FA, Collin-Vézina D, Macdonald ME. 2011. Child citizenship and agency as shaped by legal obligations. Child and Family Law Quarterly 23: 489-512.

Carnevale FA. 2012. Listening authentically to youthful voices: a conception of the moral agency of children. In Toward a Moral Horizon: Nursing Ethics for Leadership and Practice, 2nd edn. Storch JL, Rodney P Starzomski R (eds.). Pearson Education: Toronto, ON; 315-332.

Carnevale FA, Macdonald ME, Bluebond-Langner M, McKeever P. 2008. Using participant observation in pediatric health care settings: intellectual demands and ethical solutions. Journal of Child Health Care 12: 18-32.

Child Welfare Anti-Oppression Roundtable. 2009. Anti-Oppression in Child Welfare: Laying the Foundation for Change. Available at http://www.oacas.org/pubs/external/antioppressionpaper09may06.pdf [Accessed 4 February 2013]

CPS: Canadian Pediatric Society. 2004. Treatment decisions regarding infants, children and adolescents. Pediatrics Ct Child Health 9: 99-103.

Cushman F. 2008. Crime and punishment: distinguishing the roles of causal and intentional analyses in moral judgment. Cognition 108: 353-380.

Dawson K, Berry M. 2002. Engaging families in child welfare services: an evidence-based approach to best practice. Child Welfare 81: 293-317.

DiGiulio RC. 2001. Educate, medicate, or litigate? What teachers, parents, and administrators must do about student behavior. Corwin Press Inc: Thousand Oaks, CA.

Dwyer JG. 2006. Relationship Rights for Children. Cambridge University Press: Cambridge.

Eekelaar J. 1992. The importance of thinking that children have rights. In Children, Rights and the Law. Alston P, Parker S Seymour JA (eds.). Oxford University Press: Oxford; 221-235.

Finlay LL. 2007. Juvenile Justice. Greenwood Press: Westport, CT.

Fortin J. 2004. Children's Rights: are they now taking them more seriously? King's Law Journal 15: 253-272.

Gasser L, Keller ME. 2009. Are the competent the morally good? Perspective taking and moral motivation of children involved in bullying. Social Development 18: 798-816.

Gharabaghi K. 2010. Professional Issues in Child and Youth Care Practice. Routledge: New York.

Gilligan C. 1982. In a Different Voice: Psychological Theory and Woman's Development. Harvard University Press: Cambridge, MA.

Guba EG (ed.). 1990. The Paradigm Dialog. Sage: Newbury Park, Thousand Oaks, CA.

Kochanska G, Murray K, Coy KC. 1997. Inhibitory control as a contributor to conscience in childhood: from toddler to early school age. Child Development 68: 263-277.

Laible DJ, Thompson RA. 2000. Mother-child discourse, attachment security, shared positive affect, and early conscience development. Child Development 71: 1424-1440.

Lancy D. 2008. The Anthropology of Childhood: Cherubs, Chattel, Changelings. Cambridge University Press: Cambridge. 
Lee N. 2001. Childhood and Society: Growing Up in an Age of Uncertainty. Open University Press: Buckingham.

Miller G. 2010. Pediatric Bioethics. Cambridge University Press: New York.

Minow M. 1986. Rights for the next generation: a feminist approach to children's rights. Harvard Women's Law Journal 9: 1-24.

Monk D. 2002. Children's rights in education - Making sense of contradictions. Child and Family Law Quarterly 14: 45-56.

Montgomery H. 2008. An Introduction to Childhood: Anthropological Perspectives on Children's Lives. Wiley-Blackwell: Chichester.

Moran J. 2001. Interdisciplinarity. Routledge: London.

Perkins SA, Turiel E. 2007. To lie or not to lie: to whom and under what circumstances. Child Development 78: 609-621.

Pufall PB, Unsworth RP (eds.). 2004. Rethinking Childhood. Rutgers University Press: New Brunswick, NJ.

Roche J. 1999. Children: rights, participation and citizenship. Childhood 6: 475-493.

Scheper-Hughes N, Sargent C. 1998. Small Wars: The Cultural Politics of Childhood. University of California Press: Los Angeles, CA.

Shariff S. 2009. Confronting Cyber-bullying: What Schools Need to Know to Control Misconduct and Avoid Legal Consequences. Cambridge University Press: New York.

Simmons B. 2003. Child Welfare Ethics and Values. Available at http://calswec.berkeley.edu/files/ uploads/pdf/CalSWEC/Trainer_Ethics_Values.pdf [Accessed 4 February 2012].

Taylor C. 1985. Human Agency and Language: Philosophical Papers 1. Cambridge University Press: Cambridge.

Van Praagh S. 2005. Adolescence, autonomy and Harry Potter: the child as decision-maker. International Journal of Law in Context 4: 335-373.

Zelizer V. 1985. Pricing the Priceless Child: The Changing Social Value of Children. Princeton University Press: Princeton, NJ.

Correspondence to: Franco A. Carnevale, R.N., Ph.D., Professor, Ingram School of Nursing, Wilson Hall (room 210), McGill University, 3506 University St., Montreal, QC, Canada H3A 2A7, Tel.: 1-514-398-1763; Fax: 1-514-398-8455. E-mail: franco.carnevale@mcgill.ca

Accepted for publication 9 September 2013 